\title{
Efficacy of Pelvic Peritoneal Reconstruction following Laparoscopic Abdomino-Perineal Resection of the Rectum in the treatment of Lower Rectal Cancer: A comparative Study and review
}

\author{
Zafar Iqbal M.D ${ }^{1}$,Sami Ullah M.D ${ }^{2}$,Warda Mohay Uddin M.D ${ }^{3}$, \\ Dong Tang M.D, Ph.D ${ }^{4}$ Sen Wang M.D ${ }^{5}$,Muhammad Asad Iqbal ${ }^{6}$, \\ Yuqin Huang ${ }^{7}$, \\ Dao-Rong Wang M.D., Ph.D. ${ }^{*}{ }^{8}$. \\ Department Of Gastrointestinal Surgery, Subei People's Hospital, Clinical Medical College Of Yangzhou \\ University, Yangzhou City Jiangsu Province, 225001, PR China .
}

\begin{abstract}
Background: Laparoscopic abdominoperineal resection (LAPR) for rectal cancer poses a difficult challenge for surgeons regarding pelvic peritoneal reconstruction. Therefore, in this study, we investigate the effectiveness of pelvic peritoneal reconstruction following LAPR in the treatment of rectal cancer.

Methods: We retrospectively reviewed clinical data records of patients who were treated with LAPR for rectal cancer in our hospital. Patients were included if they met predetermined inclusion criteria. All included patients were divided into two groups: group A (LAPR with pelvic peritoneum reconstruction $(P P R)$ and group $B(L A P R$ without PPR). For each included patients, following data were record: age, sex, body mass index (BMI), ASA score (American society of anesthesiologists ), cancer staging, duration of operation, amount of blood loss, hospital stay, retrieved lymph nodes, time until start of flatus and oral intake and complications (early or late). Following endpoints were analyzed: operation time, intra-operative blood loss, and post-operative complication rate.

Results: A total of 146 patients underwent LAPR including 48 patients with PPR (group A) and 98 patients without PPR (group B). LAPR procedures were successful in all included patients, with no patient requiring conversion to an open approach. The mean duration of follow-up was 12 months (range, 9 to 15 months) in both groups. There was significant difference in both groups regarding operation time, duration of hospital stay and follow up, and prevalence of late complications such as intestinal obstruction and tumour recurrence $(p<0.05)$. No statistical difference was observed regarding demographic data, intra-operative blood loss and prevalence of early complications ( $p>0.05$ ).
\end{abstract}

Conclusion: LAPR technique is safe and effective procedure for patients with lower rectal cancer. Authors strongly recommend PPR following LAPR.

Keywords: laparoscopic surgery; rectal carcinoma; pelvic peritoneum; primary suturing; reconstruction

\section{Background}

Laparoscopic abdominoperineal resection (LAPR) for rectal cancer has been widely used in clinical practice [1-4]. This technique requires narrow excision of the entire pelvic floor and the anorectum but uses more radical dissection of the perianal skin or ischioanal fat compared with extralavator abdominoperineal excision (ELAPE) [5]. Numerous prospective randomized control trials have confirmed its safety and feasibility $[6,7]$. In addition, ELAPE is associated with lower risks of bowel perforation and circumferential resection margin (CRM) involvement, as well as improved cancer-pecific outcomes, compared with LAPR [8, 9]. Laparsocopic-APR poses a difficult challenge for surgeons regarding pelvic peritoneum reconstruction (PPR). Due to the requirement of longer duration of operation, prolonged anesthesia time and increased intra-operative blood loss, surgeons usually do not perform PPR [10]. However, this technique is associated with complication such as intestinal obstruction, intestinal hernia, infection and post-radiation enteritis [11]. Some recent studies [12-18] have strongly supported PPR following abdominal perineal excision (APE). However, literature still lacks enough evidence to outline strong differentiating points and it is still controversial whether to perform PPR or not? Therefore, in this study, we investigate the effectiveness of PPR following LAPR in the treatment of rectal cancer. In addition, we compare the outcomes against another cohort of patients who underwent laparoscopic LAPR without PPR. 


\section{Methods}

We retrospectively reviewed clinical data records of patients treated with Standard Laparoscopic abdominoperineal resection (LAPR) for rectal cancer in our hospital. Patients were included for study, if they met following criteria: 1 . Patients who presented with low rectal cancers $(<6 \mathrm{~cm}$ from the anal verge, judged by multi-disciplinary team not to be suitable for a coloanal anastomosis). 2. Patients aged more than 18 years. Patients were excluded if; 1.Patients in which PPR was performed using biological mesh. All included patients were divided into two groups: group A (LAPR with PPR) and group B (LAPR without PPR). For each included patients, following data were record: age, sex, body mass index (BMI), ASA score, (Table1) cancer staging (Table3), duration of operation, amount of blood loss, hospital stay, retrieved lymph nodes, time until start of flatus and oral intake (Table2) and complications (early or late) (Table4).

The diagnosis was based on blood tests, colonoscopy, rectal biopsies, and CT and MRI scans. The patients were also assessed for distant metastases. Cancer staging was done according to AJCC-TNM staging [11]. This study was conducted under the guidance of local ethical committee and strong supervision of institutional review board.

\begin{tabular}{|c|c|c|c|}
\hline Variables & group A (48) & group B (98) & $\mathrm{p}$ value \\
\hline Age (years) & $58.9 \pm 10.1$ & $61.1 \pm 10.6$ & 0.227 \\
\hline Sex & & & 0.281 \\
\hline Male & $29(60.4 \%)$ & $68(69.4 \%)$ & \\
\hline Female & $19(39.6 \%)$ & $30(30.6 \%)$ & \\
\hline BMI (kg/m2) & $25.3 \pm 1.5$ & $25.8 \pm 1.6$ & 0.161 \\
\hline ASA score & & & 0.856 \\
\hline 1 & $16(33.3 \%)$ & $35(35.7 \%)$ & \\
\hline 2 & $29(60.4 \%)$ & $55(56.1 \%)$ & \\
\hline 3 & $3(6.3 \%)$ & $8(8.2 \%)$ & \\
\hline
\end{tabular}

\begin{tabular}{|lccc|}
\hline \multicolumn{1}{|l|}{ Table 2: } & Operative and postoperative recovery data & \\
\hline Variables & group A & group B & p value \\
\hline Operative time (min) & $153.5 \pm 13.4$ & $128.5 \pm 11.9$ & $0.02^{*}$ \\
\hline Blood loss (ml) & $48 \pm 12.5$ & $51 \pm 11.2$ & 0.501 \\
\hline Retrieved Lymph nodes & $12 \pm 4$ & $12 \pm 3$ & 0.329 \\
\hline Time until start of flatus(days) & $1.5 \pm 0.5$ & $2 \pm 0.5$ & $0.014^{*}$ \\
\hline Time until start of oral intake(days) & $2 \pm 0.5$ & $2.5 \pm 1$ & $0.017^{*}$ \\
\hline Postoperative hospital stay (days) & $6.5 \pm 4.5$ & $8 \pm 5.5$ & $0.001^{*}$ \\
\hline group A: LAPR with PPR ; group B: & LAPR without PPR \\
\hline
\end{tabular}

\section{Surgical Method}

Preoperatively, mechanical bowel preparation and routine laboratory tests were done and all the test results were obtained. All patients were explained thoroughly about the risks and benefits of the procedure and written informed consent was obtained. All surgeries were performed by the same surgical team, under general anesthesia following standard laparoscopic surgery principle. Mechanical bowel preparation was carried out with sodium phosphates oral solution. Adequate dosage of parenteral broad spectrum antibiotics consisting of Cefuroxime $1500 \mathrm{mg}$ and Metronidazole $500 \mathrm{mg}$ were administered intravenously at induction of anesthesia. Urinary catheter was routinely used. One set of surgeons performed abdominal phage and another set of surgeons performed perineal phage to reduce the duration of operation. LAPR was performed in accordance with the principles described by Jun Han et al. [19, 38], except that the abdominal phase was performed as a regular laparoscopic rectal surgery [20]. We followed a five-trocar conventional technique. The operation was performed according to the following seven procedural steps. First, a 12-mm superumbilical port was established to create a pneumoperitoneum with a pressure of $12-15 \mathrm{~mm} \mathrm{Hg}$, and the laparoscopic camera was introduced through this trocar. Under direct laparoscopic visualization, the other four trocars were inserted. The sigmoid colon omentum adhesion was resected to free colon from left abdominal wall (Figure 1). The mesorectum was opened along Toldt's space by an electric knife. If necessary, intraoperative excisional biopsy or cytological examinations were performed. Second, mobilization of both the jejunum and the ileum was done in right-head-ventral side. This mobilization was indicated to provide a good operative view of the left side of the colon. Our devise performed to put on half gauze near the ligament of Treitz and right iliac artery. This reason is not so good with operation's view in order to the intervention of small intestine Dissection of the left side of the colon was performed from a medial-to-lateral retroperitoneal approach.

Third, lymphadenectomy around the inferior mesenteric artery (Figure 2) and ligation of this artery were performed (Figure 3). Retroperitoneal dissection was performed from a medial-to-lateral approach. Fourth, mobilization of the rectum and excision of the mesorectum were performed. We accessed the deepest part of the 
pelvic cavity by retracting the rectum toward the dorsal side. We identify the levator ani muscle as a device at this time and excise a portion of this muscle from the abdominal cavity. We consider it very useful to continue between the vulval orifice and intra-abdominal cavity. At this point in the procedure, the proximal rectum (recto-sigmoid section, Rs) is cut with a stapling device (Endo Tri-Staple ${ }^{\mathrm{TM}}$ Technology) (Figure 4).Fifth, with the help of the perineal surgeon, the rectum together with the whole mesorectum was fully mobilized, and the specimen was retrieved through the perineal wound. The perineal wound was closed in the pelvic cavity via a separate stab wound, primarily by suturing of the remnant part of the pelvic floor as well as perianal skin. Perineum was closed with insertion of closed suction perineal drainage cathether was used and kept negative pressure always, which was removed when drainage was minimal. Potassium permanganate was used for hip bath after removing the stitches.

Sixth in (group A) patients, laparoscopic PPR was performed following removal of specimen provided enough tissue for closure without undue tension. The peritoneum should be sufficiently lax to descend to the level of the reconstruction using absorbable monofilament tension free sutures. We used violet monofilament synthetic absorbable 2-0 sutures for the reconstruction. The procedure involved fixation of the cut edges to reperitonealize the pelvic peritoneum by continuous suturing [15, 16] (Figure 5 and 6). Then, all remaining trocar sites were closed. In group B patients, PPR was not performed and trocar sites were closed prior to perineal phage.

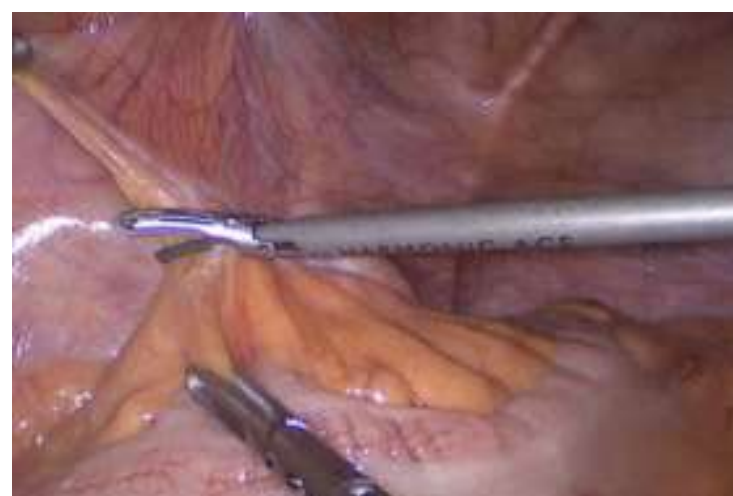

Figure1. Sigmoid colon omentum adhesion.

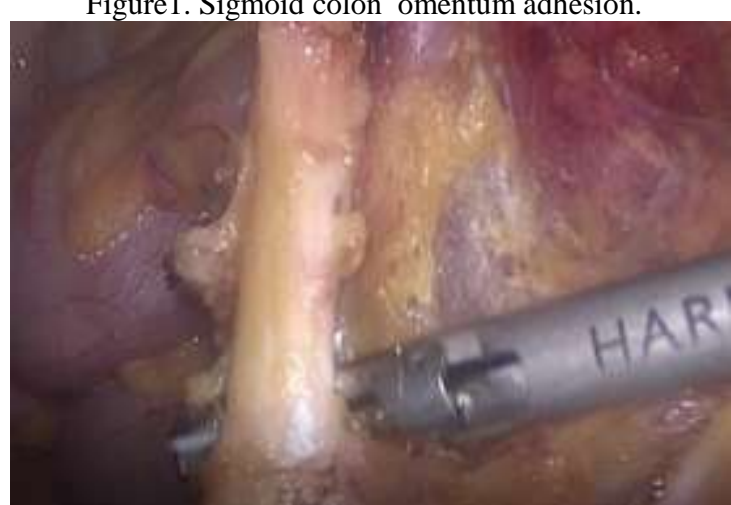

Figure3.Inferior mesenteric artery (IMA) resection

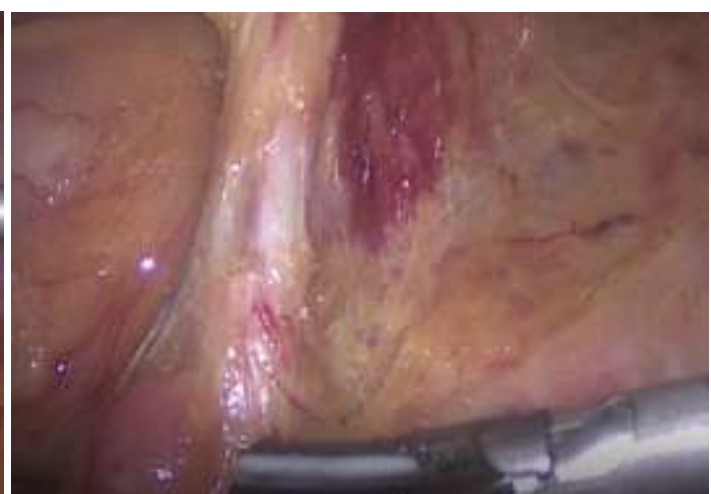

Figure2. lymph node dissection around IMA

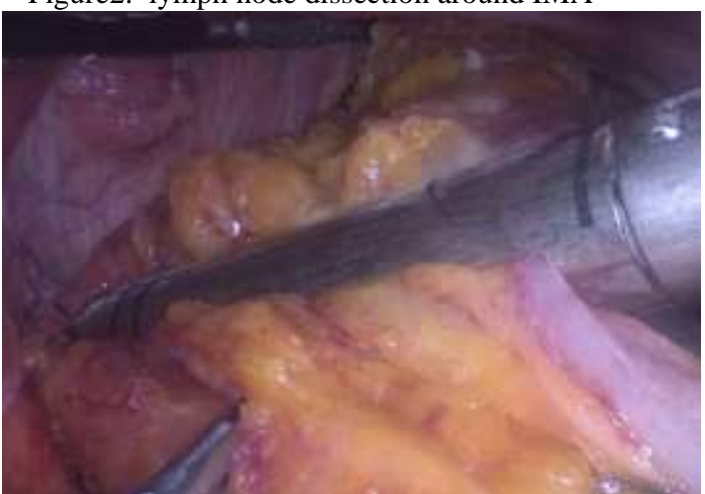

Figure4. (recto-sigmoid section) with stapping device 

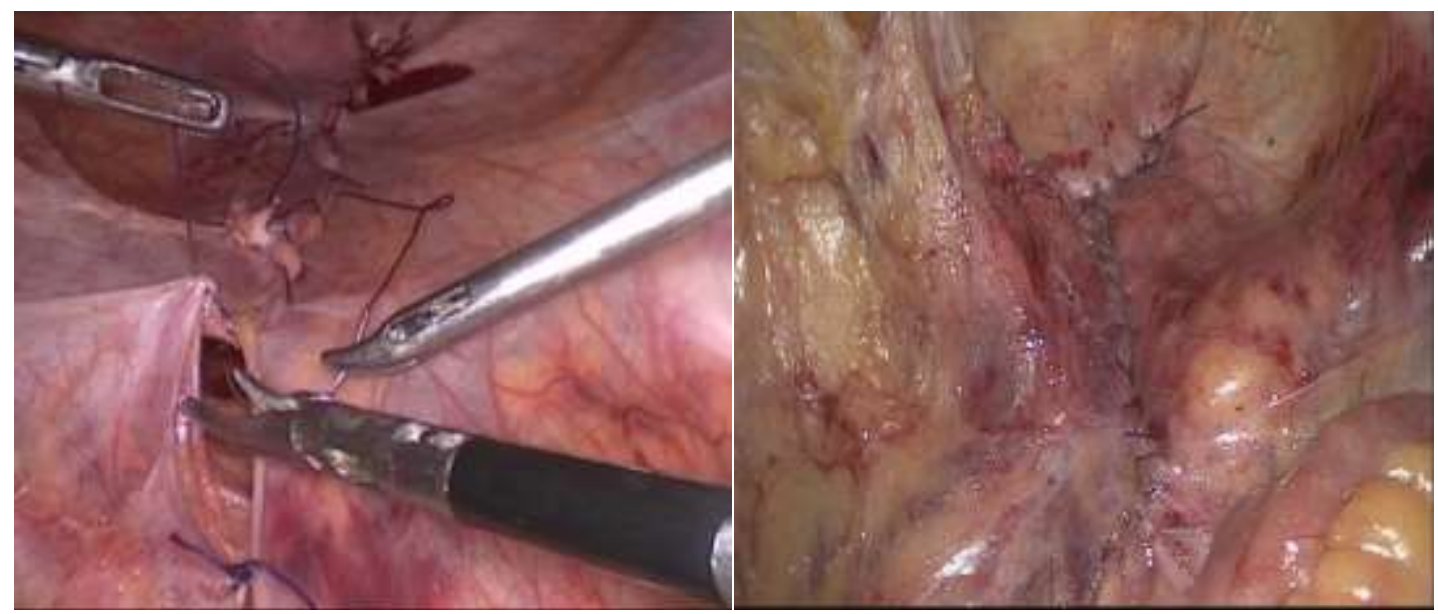

Figure5 and 6. Reperitonealize the pelvic floor peritoneum (PPR) by continous suturing

\section{Follow-up and outcome analysis}

All patients were followed up every 3 to 6 months. Blood tests, including serum tumor markers, chest and abdominal CT scans and colonoscopy were performed every 6 months, and repeated every 1 year if no lesions were found for about 3 years. Data collection, synthesis and analysis were done using SPSS 17.0 software ${ }^{\circledR} 139$ and following endpoints were analyzed: operation time, intra-operative blood loss, and postoperative complication rate. Level of significance was set on 0.05 .

\section{Demographics of patients}

\section{Results}

A total of 146 patients underwent LAPR including 48 patients with PPR (group A) and 98 patients without PPR (group B).Group A $(\mathrm{n}=48)$ included 29 men and 19 women who underwent LAPR with PPR for rectal cancer between November 2014 and July 2016. Patients' age ranged from 38 to 79 years (average, $58.9 \pm 10.1$ years). The average body mass index (BMI) was $25.3 \pm 1.5 \mathrm{~kg} / \mathrm{m} 2$ (range, 22.3 to $28 \mathrm{~kg} / \mathrm{m} 2$ ). Rectal cancer staging included T1N0M0 (3 patients), T1N1M0 (1 patient), T2N0M0 (10 patients), T2N1M0 (6 patients), T3N0M0 (13 patients), T3N1M0 (6 patients), T4N1M0 (2 patients), T4N1M1 (1 patients), T4N2M0 (4 patients), T4N2M1 (2 patients). Group B ( $\mathrm{n}=98)$ included 68 men and 30 women who underwent LAPR without PPR for rectal cancer between August 2012 and November 2014. Patients' age ranged from 37 to 81 years (average, $61.1 \pm 10.6$ years). The average body mass index (BMI) was $25.8 \pm 1.6 \mathrm{~kg} / \mathrm{m} 2$ (range, 22.1 to 28.2 $\mathrm{kg} / \mathrm{m} 2$ ). Rectal cancer staging included T1N0M0 (5 patients), T1N1M0 (1 patient), T1N2M0 (1 patient), T2N0M0 (25 patients), T2N1M0 (7 patients), T2N2M0 (1 patient) T2N2M1 (1 patient), T3N0M0 (22 patients), T3N1M0 (6 patients), T3N1M1 (1 patient), T3N2M0 (5 patients), T3N2M1 (1 patient), T4N0M0 (9 patients), T4N1M0 (8 patients), T4N1M1 (1 patient) T4N2M0 (3 patients), T4N2M1 (1 patient) [Table 3]. No statistical difference was observed regarding demographic data [Table1], intra-operative blood loss [Table2] $(p>0.05)$ [Table 4]. There was significant difference in both groups regarding operation time, duration of hospital stay, time until start of flatus, oral intake follow up, and prevalence of late complications $(\mathrm{p}<0.05)$. Comparisons between both groups showed no differences regarding oncological result from the pathology report and prevalence of early complications. There was no significant difference regarding complications in the LAPR Group with PPR. Whereas intestinal obstruction was significantly more often found in the LAPR without PPR group B (Table 4)

\begin{tabular}{|lllr|}
\hline Table 3: Clinicopathologic data & & & \\
\hline Variables & group A $(48)$ & group B (98) & p value \\
\hline Tumor size $(\mathrm{cm})$ & $3.5 \pm 1.4$ & $3.7 \pm 1.2$ & 0.242 \\
\hline Mean tumour height $(\mathrm{cm})^{*}$ & & & 0.149 \\
\hline Tumour height $<4 \mathrm{~cm}$ & $31(64.6 \%)$ & $76(77.6 \%)$ & \\
\hline Tumour height 4-6cm & $17(35.4 \%)$ & $22(22.4 \%)$ & \\
\hline T stage & $4(8.3 \%)$ & $7(7.1 \%)$ & 0.937 \\
\hline T1 & $16(33.3 \%)$ & $34(34.7 \%)$ & \\
\hline T2 & $19(39.6 \%)$ & $35(35.7 \%)$ & \\
\hline T3 & $9(18.8 \%)$ & $22(22.5 \%)$ & \\
\hline T4 & & & \\
\hline N stage & $26(54.2 \%)$ & $61(62.2 \%)$ & \\
\hline 0 (N0) & & \\
\hline
\end{tabular}


Efficacy Of Pelvic Peritoneal Reconstruction Following Laparoscopic.....

\begin{tabular}{|c|c|c|c|}
\hline $1-3(\mathrm{~N} 1)$ & $16(33.3 \%)$ & $24(24.5 \%)$ & \\
\hline$\geq 4(\mathrm{~N} 2)$ & $6(12.5 \%)$ & $13(13.3 \%)$ & \\
\hline M stage & & & 0.775 \\
\hline M0 & $45(93.8 \%)$ & $93(94.9 \%)$ & \\
\hline M1 & $3(6.2 \%)$ & $5(5.1 \%)$ & \\
\hline TNM stage (AJCC 7th) & & & 0.828 \\
\hline I & $14(29.2 \%)$ & $32(32.7 \%)$ & \\
\hline II & $13(27.1 \%)$ & $31(31.6 \%)$ & \\
\hline III & $18(37.5 \%)$ & $30(30.6 \%)$ & \\
\hline IV & $3(6.2 \%)$ & $5(5.1 \%)$ & \\
\hline $\begin{array}{l}\text { group A: LAPR with } \mathrm{P} \\
\text { Metastasis }\end{array}$ & LAPR witho & umour $\mathrm{N}$ : $\mathrm{Nc}$ & vement $\mathrm{M}$ \\
\hline
\end{tabular}

\section{Surgical outcomes}

LAPR was successful in all included patients, with no patient requiring conversion to an open approach. The mean duration of follow-up was 12 months (range, 9 to 15 months) in both groups. In group A, the average duration of operation was $153.5 \pm 13.4 \mathrm{~min}$ (range, 110 to $200 \mathrm{~min}$ ). The average amount of blood loss was $48 \pm 12.5 \mathrm{ml}$ (range, 30 to $300 \mathrm{ml}$ ). The average duration of hospital stay was $6.5 \pm 4.5$ days (range, 6 to 20 days). Early complications within 30 postoperative days included bleeding ( 0 patients, $0 \%)$, perineal wound infection (6 patient, $12.5 \%)$, infection of the stoma (2 patients, $4.2 \%$ ), dysurea (5 patients, $10.4 \%$ ), reoperation (0 patients, $0 \%)$. Late Complications included local tumor recurrence (2 patient, 4.2\%), intestinal obstruction (1 patient, $2.1 \%$ ), intestinal hernia (0 patient, $0 \%$ ). In group B, the average duration of operation was $128.5 \pm 11.9$ min (range, 100 to $175 \mathrm{~min}$ ). The average amount of blood loss was $51 \pm 11.2 \mathrm{ml}$ (range, 30 to $300 \mathrm{ml}$ ). In addition, average duration of hospital stay was $8 \pm 5.5$ days (range, 6 to 24 days). Early complications within 30 postoperative days included bleeding ( 2 patients, $2.0 \%$ ), perineal wound infection (10 patient, 10.2\%), infection of the stoma (5 patients, $5.1 \%$ ), dysurea (13 patients, $13.3 \%$ ), reoperation ( 3 patients, $3.1 \%$ ). Late Complications included local tumor recurrence (18 patient, 18.4\%), intestinal obstruction (12 patient, 12.2\%), intestinal hernia (1 patient, 1\%). There was no statistical difference observed regarding demographic data such as Age, sex, BMI and ASA score [Table1]. There was significant difference in both groups regarding operation time, time until start of flatus, oral intake follow up, duration of hospital stay [Table2]. There was no statistical difference observed in both the groups regarding intra-operative blood loss and prevalence complications such as stomal and intestinal hernia, bleeding, infection of stoma, dysurea and perineal wound infection ( $p>0.05)$ [Table4]. There was a significant difference observed regarding intestinal obstruction $(\mathrm{P}=0.043)$ as well as in tumor recurrence $(\mathrm{P}=0.019)$ in both the groups. [Table 4]

\begin{tabular}{|lccc|}
\hline Table 4: Postoperative complications & & & \\
\hline Variables & group A(n=48) & group B(n=98) & p value \\
\hline Intestinal obstruction & $1(2.1 \%)$ & $12(12.2 \%)$ & $0.043^{*}$ \\
\hline Stomal hernia & $3(6.3 \%)$ & $5(5.1 \%)$ & 0.775 \\
\hline Intestinal hernia & $0(8.3 \%)$ & $1(1 \%)$ & 0.483 \\
\hline Bleeding & $0(0) \%$ & $2(2.0 \%)$ & 0.319 \\
\hline Infection of stoma & $2(4.2 \%)$ & $5(5.1 \%)$ & 0.804 \\
\hline Infection of perineal incision & $6(12.5 \%)$ & $10(10.2 \%)$ & 0.677 \\
\hline Reoperation & $0(0 \%)$ & $3(3.1 \%)$ & 0.213 \\
\hline Dysuria & $5(10.4 \%)$ & $13(13.3 \%)$ & 0.623 \\
\hline Tumor recurrence & $2(4.2 \%)$ & $18(18.4 \%)$ & $0.019^{*}$ \\
\hline group A : LAPR with PPR ; group B : LAPR without PPR & & \\
\hline
\end{tabular}

\section{Discussions}

Most authors now agree to the fact that with advancement in laparoscopic surgical technique, surgeons nowadays are more interested towards laparoscopic resection surgeries [22-25]. Laparoscopic rectal cancer resection surgery has many advantages, such as less blood loss, shorter duration of hospital stay and early recovery. Several previous studies have proven the safety and feasibility of laparoscopic rectal cancer resection surgery [22-25]. There are some disadvantages as well, including technical difficulties and conversion to open approach [22, 23]. However, more recent studies have shown no laparoscopic procedure required conversion to open surgery [24, 25]. PPR following LAPR has been an area of discussion for long time [11-15, 17]. Previously, because of longer duration of operation, increased level of difficulties of tying knot, and risk of bowel perforation, surgeons do not usually perform PPR following LAPR [11, 13]. However, this technique may result in high prevalence of complications, such as wound infection, intestinal obstruction, persistent sinus formation, or post-radiation enteritis [11]. Nowadays, laparoscopic surgeons are highly encouraged to perform PPR following LAPR [12, 16 and 17]. There are various techniques, ranging from primary suturing to biological mesh [12-14]. However, the optimal method has not been determined. Primary suturing is cost-effective and 
easily available. However, some authors have reported complications, such as loosening of the knot causing intestinal hernia and obstruction, tightening of knot causing peritoneal necrosis and widespread infection, and occasionally occurrence of fistulae $[11,13]$. Despite these complications, most studies recommended primary suturing technique with sutures applied in normal tension. In this study there was no difference in demographic distribution, including age, sex, BMI and tumor staging in both the groups . Patients who underwent LAPR with PPR showed lower duration of hospital stay and lower prevalence of late complications than patients who underwent LAPR without PPR.

Patients without PPR required longer duration of follow-up because of increased prevalence of late complications along with high risk of recurrence. These results suggested that patients who underwent PPR following LAPR recover early with lower risk of recurrence. However, the duration of operation was longer in patients who underwent PPR. In addition, there was no significant difference regarding prevalence of early complications. In addition, previous studies reporting PPR using biological mesh [14]. In this study, we observed that PPR following LAPR technique is safe and effective procedure for patients with low rectal cancer. As LAPR is associated with worse outcomes compared with anterior resection in terms of local recurrence and overall prognosis it requires improved surgical technique [5]. In LAPR, inadequate resection leads to increased risk of positive CRM and perforation. To improve patient survival, ELAPE proven to be effectively reduce CRM involvement and bowel perforation [26, 27]. However, there were also researches showed that ELAPE not always reduces CRM positivity [28]. Recently, radical ELAPE technique [21] has evolved as a very good alternative which is associated with low rates of CRM involvement and improved oncological outcomes. However, radical ELAPE required open approach to the abdominal portion of the operation [21]. To study the short and long-term outcome of a new operative technique like ELAPE in comparison to a gold standard like APE a prospective, randomised, controlled study would be the preferred method as has been done for example for laparoscopic colon and rectal cancer surgery [32,33]. In 2015 a systematic review and meta-analysis by Zhou and colleagues was published. The study included, previously known risk factors for local recurrence i.e. intraoperative perforations, more advanced T-stage and lymph-node-stage was found to be associated with increased risk of local recurrence, but also ELAPE itself when compared to standard APE. For the patients of the more distal tumours ELAPE is not associated with higher risk for local recurrence but no advantage could be shown with ELAPE compared to standard APE, this meta-analysis did not find a statistically significant advantage of ELAPE over conventional APE in terms of CRM positivity [34, 35]. West et al [29,30] reported a lower perforation rate and fewer cases with involved CRM using ELAPE in case series in comparison with histological controls that has high rates of perforations and involved margins. Stelzner et al [31]. . There is a clear indication in several studies that ELAPE was associated with increased morbidity in relation to the perineal surgical wound, and since this is well in line with what could be expected this is likely to be a true disadvantage of this technique [36, 37]. The principle hypothesis that ELAPE by decreasing intraoperative perforations and involved CRM can decrease the rates of local recurrence has however not been shown with clarity. A large proportion of survivors after abdominoperineal excision for rectal cancer have a quality of life comparable to a normative population, however many suffer from a symptom of stress, negative intrusive thoughts, which significantly decrease overall quality of life. General conclusion ELAPE should not be suggested as a standard operative technique for all low rectal cancers. ELAPE should be used with discretion, primarily for cases with high risk of intra operative perforation which is a major risk factor for local recurrence. The discussion was instead focused on another important topic related to standard LAPR with pelvic peritoneum reconstruction PPR and the best way of closing the defect. Other variables that can be attributes are surgeonrelated variables such as level of training, past experience and annual numbers of operations performed.

\section{Conclusions}

LAPR technique is safe and effective procedure for patients with low rectal cancer. PPR following LAPR is feasible with acceptable risk of complications. Except for the duration of operation, all the other outcome parameters were satisfactory among patients who underwent PPR. Hence, authors strongly recommend PPR following LAPR. However, further studies are required to establish strong evidence regarding high efficacy of PPR following LAPR and standard procedures for lower rectal cancer resection.

\section{Declarations}

List of Abbreviations: LAPR: laparoscopic abdominal perineal reconstruction; ELAPE: extralevator abdominoperineal excision; PPR: pelvic peritoneal reconstruction; APE: standard abdominio perineal excision; BMI: body mass index; CRM: circumferential resection margin; CT: computed tomography; MRI: magnetic resonance imaging

Ethical approval and consent to participate: This study is approved by local ethical committee of Subei People's Hospital; all the included patients voluntarily provided the consents for both the surgery and participation in the study. 
Consent for publication: Not applicable

Availability of data and materials: We do not wish to share, because this study is a beginning of a very large scale study, and we are hesitant to share the primitive information just to avoid publication misconduct.

\section{Competing interest: N/A}

Source of funding: N/A

\section{Author's contributions}

1. Zafar Iqbal: made substantial contributions to conception and design, or acquisition of data, or analysis and interpretation of data; agreed to be accountable for all aspects of the work in ensuring that questions related to the accuracy or integrity of any part of the work are appropriately investigated and resolved Samiullah: made substantial contributions to conception and design, or acquisition of data, or analysis and interpretation of data

Warda Mohay Uddin: made substantial contributions to conception and design, or acquisition of data, or analysis and interpretation of data

Dong Tang: been involved in drafting the manuscript or revising it critically for important intellectual content Dao-rong Wang: been involved in drafting the manuscript or revising it critically for important intellectual content; given final approval of the version to be published. Each author should have participated sufficiently in the work to take public responsibility for appropriate portions of the content; agreed to be accountable for all aspects of the work in ensuring that questions related to the accuracy or integrity of any part of the work are appropriately investigated and resolved

Sen Wang: been involved in drafting the manuscript or revising it critically for important intellectual content Muhammad Asad iqbal: involved in drafting the manuscript or revising it critically for important intellectual content

Yuqin Huang: made substantial contributions to conception and design, or acquisition of data, or analysis and interpretation of data

\section{Acknowledgements}

Subhash Regmi M.D., College of Medicine, Yangzhou University for his technical help.

\section{References}

[1]. Wang Z1, Zhang XM, Liang JW, Hu JJ, Zeng WG, Zhou ZX. Evaluation of short-term outcomes after laparoscopically assisted abdominoperineal resection for low rectal cancer.ANZ J Surg. 2014 Nov;84(11):842-6. doi: 10.1111/ans.12518. Epub 2014 Jan 24.

[2]. Yu-Wei Wang, Li-Yong Huang, Cheng-Li Song, Chang-Hua Zhuo Laparoscopic vs open abdominoperineal resection in the multimodality management of low rectal cancersWorld J Gastroenterol. 2015 Sep 21; 21(35): 10174-10183.

[3]. Takehito Yamamoto, Akiyoshi Kanazawa, Hiroyuki Matsubara, and Takuya Okamoto. Safety and usefulness of needle-guided resection of levator muscles in laparoscopic abdominoperineal resection for low rectal cancer. Wideochir Inne Tech Maloinwazyjne. 2016; 11(3): 186-191.

[4]. Shukla PJ1, Barreto SG, Hawaldar R, Nadkarni M, Kanitkar GA, Kerkar R, Shrikhande SV.et al. Feasibility of laparoscopic abdomino-perineal resection for large-sized anorectal cancers: a single-institution experience of 59 cases. Indian J Med Sci. 2009 Mar;63(3):109-14.

[5]. Perdawood SK, Lund T. Extralevator versus standard abdominoperineal excision for rectal cancer. Tech Coloproctol 2015;19: 145152.

[6]. Ohtani H, Tamamori Y, Azuma Y, Nishiquch Y, Maeda K, Hirakawa K: A meta-analysis of the short- and long-term results of randomized controlled trials that compared laparoscopy assisted and conventional open surgery for rectal cancer. J Gastrointest Surg 2011, 15:1375-1385.

[7]. Guillou PJ, Quirke P, 'T'horpe H, et al Short-term end- points of conventional versus laparoscopic-assisted surgery in palients with rectal cancer (MRC CI.ASICC trial): multi. cemre, randomized controlled I rial [-J] Lancet, 2005,365: 1718

[8]. Zaharie F, Ciorogar G, Zaharie R, Mocan T, Zdrehus C, Mocan L, Berindan-Neagoe I, Achimas P, Iancu C, Tomus C. Laparoscopic rectal resection versus conventional open approach for rectal cancer - a 4-year experience 305 of a single center. J BUON. 2015; 20:1447-55.

[9]. Vaughan-Shaw PG, King AT, Cheung T, Beck NE, Knight JS, Nichols PH, Nugent KP, Pilkington SA, Smallwood JA, Mirnezami AH: Early experience with laparoscopic extralevator abdominoperineal excision within an enhanced recovery setting: analysis of short-term outcomes and quality of life. Ann R Coll Surg Engl 2011, 93:451

[10]. Sackier JM, Berci G, Hiatt JR, Hartunian S: Laparoscopic abdominoperineal resection of the rectum. Br J Surg 1992, 79:12071208.

[11]. Chen JS, ChangChien CR, Wang JY, Fan HA. Pelvic peritoneal reconstruction to prevent radiation enteritis in rectal carcinoma. Dis Colon Rectum. 1992;35: 897901

[12]. Han JG, Wang ZJ, Gao ZG, Xu HM, Yang ZH, Jin ML: Pelvic floor reconstruction using human acellular dermal matrix after cylindrical abdominoperineal resection. Dis Colon Rectum 2010, 53:219-223.

[13]. De Broux E, Parc Y, Rondelli F, Dehni N, Tiret E, Parc R. Sutured perineal omentoplasty after abdominoperineal resection for adenocarcinoma of the lower rectum. Dis Colon Rectum. 2005; 48:476-82

[14]. Wille-Jorgensen P, Pilsgaard B, Moller P: Reconstruction of the pelvic floor with a biological mesh after abdominoperineal excision for rectal cancer. Int J Colorectal Dis 2009, 24:323-325 
[15]. Aura T, Habib E, Mekkaoui M, Brassier D, Elhadad A. Laparoscopic tension-free repair of anterior abdominal wall incisional and ventral hernias with an intraperitoneal Gore- Tex mesh: prospective study and review of the literature. J Laparoendosc Adv Surg Tech A 2002; 12: 263-267.

[16]. Druzijanic' N, Perko Z, Srsen D, Pogorelic' Z, 328 Schwarz D, Juricic' J. Pelvic peritonization after laparoscopic abdominoperineal resection for low-rectal carcinoma treatment: surgical technique. Hepatogastroenterology. 2009;56: 1028-31.

[17]. Matsuhashi N, Takahashi T, Nonaka K, Tanahashi T, Hisashi I, Sasaki Y, Tanaka Y,Okumura N, Yamaguchi K, Osada S and Yoshida K. Laparoscopic technique and safety experience with barbed suture closure for pelvic cavity after abdominoperineal resection.World Journal of Surgical Oncology 2013 11:115.

[18]. Moreaux J, Horiot A, Barrat F, Mabille J. Obliteration of the pelvic space with pedicled omentum after excision of the rectum for cancer. Am J Surg. 1984; 148: 640-4.

[19]. Jun Han,1 Chuanbing Shi,2 Xiaogang Dong,1 Jie Wang,1 Hao Wen,1 Baolin Wang,1 and Zhenyu He1,Laparoscopic abdominoperineal resection for patients with anorectal malignant melanoma: a report of 4 cases. J Biomed Res. 2016 Sep; 30(5): 436-440.

[20]. Yang X, Jin C, Deng X, Wang M, Zhang Y, Wei M, Meng W, Wang Z.

[21]. Laparoscopic Extralevator Abdominoperineal Excision of the Rectum with Primary Suturing: Short-TermOutcomes from SingleInstitution Study. J

[22]. Laparoendosc Adv Surg Tech A. 2016; 26: 40-6

[23]. Mulsow J, Winter DC. Extralevator abdominoperineal resection for low rectal cancer: New direction or miles behind? Arch Surg 2010;145:811-813

[24]. Larach SW, Salomon MC, Williamson PR, Goldstein E: Laparoscopic assisted abdominoperineal resection. Surg Laparosc Endosc 1993, 3:115-118.

[25]. Iroatulam AJ, Agachan F, Alabaz O, Weiss EG, Nogueras JJ, Wexner SD: Laparoscopic abdominoperineal resection for anorectal cancer. Am Surg 1998, 64:12-18

[26]. Raftopoulos I, Reed JF, Bergamaschi R: 350 Circumferential resection margininvolvement after laparoscopic abdominoperineal resection for rectal cancer. Colorectal Dis 2012,

[27]. 14:431-437

[28]. Pikarsky AJ, Rosenthal R, Weiss EG, Wexner SD: Laparoscopic total mesorectal excision. Surg Endosc 2002, 16:558-562.

[29]. Shen Z, Ye Y, Zhang X, Xie Q, Yin M, Yang X, Jiang K, Liang B, Wang S. Prospective controlled study of the safety and oncological outcomes of ELAPE procure with definitive anatomic landmarks versus conventional APE for lower rectal cancer. Eur J Surg Oncol 2015; 41:472-477.

[30]. Han JG, Wang ZJ, Wei GH, Gao ZG, Yang Y, Zhao BC. Randomized clinical trial of conventional versus cylindrical abdominoperineal resection for locally advanced lower rectal cancer. Am J Surg 2012; 204:274-282.

[31]. Perdawood SK1, Lund T. Extralevator versus standard abdominoperineal excision for rectal cancer. Tech Coloproctol. 2015; 19:145-52.

[32]. West NP, Finan PJ, Anderin C, Lindholm J, Holm T, Quirke P. Evidence of the

[33]. oncologic superiority of cylindrical abdominoperineal excision for low rectal cancer. J

[34]. Clin Oncol. 2008;26(21):3517-3522. doi: 10.1200/JCO.2007.14.5961.

[35]. West NP, Anderin C, Smith KJ, Holm T, Quirke P. Multicentre experience with extralevator abdominoperineal excision for low rectal cancer. Br J Surg 97(4):588-99

[36]. Stelzner S, Koehler C, Stelzer J, Sims A, Witzigmann H. Extended abdominoperineal excision vs. standard abdominoperineal excision in rectal cancer--a systematic overview.

[37]. van der Pas MH, Haglind E, Cuesta MA, et al. Laparoscopic versus open surgery for rectal cancer (COLOR II): short-term outcomes of a randomised, phase 3 trial. Lancet Oncol; 14(3):210-218.

[38]. Bonjer HJ, Deijen CL, Abis GA, et al. A randomized trial of laparoscopic versus open surgery for rectal cancer. N Engl J Med 2015; 372(14):1324-1332

[39]. Ortiz H, Ciga MA, Armendariz P, et al. Multicentre propensity scorematched analysis of conventional versus extended abdominoperineal excision for low rectal cancer. Br J Surg 2014; 101(7):874-882.

[40]. Klein M, Fischer A, Rosenberg J, et al. ExtraLevatory AbdominoPerineal Excision (ELAPE) Does Not Result in Reduced Rate of Tumor Perforation or Rate of Positive Circumferential Resection Margin: A Nationwide Database Study. Ann Surg 2014.

[41]. Asplund D, Haglind E, Angenete E. Outcome of extralevator abdominoperineal excision compared with standard surgery. Results from a single centre. Colorectal Dis.2012 Oct;14(10):1191-6.

[42]. 37.Asplund D, Prytz M, Bock D, et al. Persistent perineal morbidity is common following abdominoperineal excision for rectal cancer. Int J Colorectal Dis 2015; 30(11):1563-1570.

[43]. Nobuhisa Matsuhashi,1 Takao Takahashi,1 Kenichi Nonaka,1 Toshiyuki Tanahashi,1 Laparoscopic technique and safety experience with barbed suture closure for pelvic cavity after abdominoperineal resection. World J Surg Oncol. 2013; 11: 115. 